\title{
Grain yield and phosphorus use efficiency of wheat and pea in a high yielding environment
}

\author{
P. Sandaña ${ }^{1 *} \&$ D. Pinochet ${ }^{2}$ \\ ${ }^{1}$ Graduate School, Faculty of Agricultural Sciences, Universidad Austral de Chile. Valdivia, Chile. \\ *Corresponding author: patricio.sandana@inia.cl \\ ${ }^{2}$ Institute of Agricultural Engineering and Soil Science, Universidad Austral de Chile. Valdivia, Chile
}

\begin{abstract}
The aim of the present study was to evaluate the response of grain yield, phosphorus (P) use efficiency (PUE, $\mathrm{g}$ yield $\mathrm{g}^{-1} \mathrm{P}$ available) and related root traits of wheat and pea to different $\mathrm{P}$ availabilities in a high yielding environment (e.g.: yield higher than $10 \mathrm{Mg} \mathrm{ha}^{-1}$ for wheat). Two experiments were conducted in southern Chile. Treatments consisted of the combination of (i) two crops (spring-bred wheat and pea) and (ii) three rates of $\mathrm{P}$ fertilization (0 (P0), $100(\mathrm{P} 1)$ and $\left.250(\mathrm{P} 2) \mathrm{kg} \mathrm{P} \mathrm{ha}^{-1}\right)$. Grain yield of wheat was more sensitive to P deficiency than pea. Wheat showed consistently higher $(P<0.01)$ PUE than pea, averaging 195 and $125 \mathrm{~g}_{\text {yield g }}{ }^{-1} \mathrm{P}$ available, respectively. This was principally ascribed to the highest $(P<0.01) \mathrm{P}$ utilization efficiency of wheat (430 vs. $249 \mathrm{~g}$ yield $\mathrm{g}^{-1} \mathrm{P}$ uptake for wheat and pea, respectively). On the contrary, the P uptake efficiency was slightly different for these crops ( 0.44 and $0.49 \mathrm{~g} \mathrm{P} \mathrm{g}^{-1} \mathrm{P}$ available, respectively). However, these crops presented different strategies for $\mathrm{P}$ acquisition. Wheat had a higher $(P<0.01)$ soil exploratory capacity than pea, while pea showed a higher $(P<0.01)$ P uptake per unit of root length than wheat. Wheat showed higher PUE than pea; however, crop differences are ascribed to differences in phosphorus utilization rather than to phosphorus uptake efficiency. This information could contribute to optimized soil $\mathrm{P}$ use and improved crop fertilization management.
\end{abstract}

Keywords: Pea, phosphorus, uptake, wheat, yield

\section{Introduction}

Today, there is concern about the scarcity of future $\mathrm{P}$ sources for agriculture, since phosphate rock could be depleted in the next 50 to 100 years (Cordell et al., 2009). In addition, more important than the amount of $\mathrm{P}$ in the ground, is how much it will cost to get it out. In consequence, the strategic dimensions of $\mathrm{P}$ are beginning to be recognized (Elser and Bennett, 2011). Soil phosphorus $(\mathrm{P})$ deficiency is a major constraint to increased crop yields in many areas of the world (Vance et al., 2003). Relative to nitrogen and potassium, the recovery of $\mathrm{P}$ fertilizers by 
crop plants is usually very low due to soils' high capacity to fix $\mathrm{P}$ to soil constituents of little bioavailability (Manske et al., 2001; Lynch, 2007; Balemi and Negisho, 2012). Therefore, it is not surprising that since the green revolution, high amounts of $\mathrm{P}$ fertilizers have been applied to soils in order to meet the $\mathrm{P}$ demand of agricultural systems (Tilman et al., 2001). Therefore, it is currently extremely important to improve our knowledge regarding crops' grain yield sensitivities and P use efficiency (PUE) in order to sustain food production with a minimal environmental impact.

Our current understanding of PUE greatly varies depending upon the crop specie. Temperate cereals, especially wheat, have been much more investigated in terms of their PUE than temperate grain legumes, like pea (e.g. Batten, 1992; Gahoonia et al., 1999; Manske et al., 2001). In Southern Chile $\left(40^{\circ} \mathrm{S}, 70^{\circ} \mathrm{W}\right)$ wheat is the most sown grain crop and pea could also be considered as an alternative crop for plant protein production (Sandaña et al., 2009). Some field and glasshouse experiments directly comparing these crop groups have shown that wheat has a higher response to $\mathrm{P}$ supply than grain legumes (Bolland et al., 1999). However, in these studies crops were assessed under low yielding environments and PUE was not evaluated. This makes it difficult to extrapolate the sensitivity of these crops (in yield and PUE) to P deficiency under high yielding environments. In the agricultural systems of southern it is essential to make these types of comparison considering that i) wheat and pea can yield over 6 and $10 \mathrm{Mg}$ $\mathrm{ha}^{-1}$, respectively (wheat: Sandaña and Pinochet, 2011; Bustos et al., 2013; pea: Sandaña et al., 2009 ) and ii) high amounts of $P$ fertilization are often required to reach these yields, since soils in this environment are volcanic soils (Andisols) with high P fixing capacities.

Previously, Moll et al. (1982) using N, defined nutrient use efficiency as grain yield per unit of nutrient supplied (from soil plus fertilizer). Analogously, for similar components defined by Moll et al. (1982), PUE (Equation 1), can be analyzed as the product of $\mathrm{P}$ utilization efficiency (PUTE, the ability of crops to convert absorbed $\mathrm{P}$ into yield) and $\mathrm{P}$ uptake efficiency (PUPE, the ability of crops to uptake $\mathrm{P}$ from the soil). P available considers the $\mathrm{P}$ supplied from the soil plus $\mathrm{P}$ from fertilizers.

PUE $(\mathrm{g}$ yield $/ \mathrm{g}$ P available $)=$ PUTE $(\mathrm{g}$ yield $/ \mathrm{g}$ P uptake) x PUPE (g P uptake/g P available) (1) PUTE differences among wheat genotypes have been previously reported (Manske et al., 2001). Calderini et al. (1995) found that PUTE was higher in modern wheat cultivars when compared to older cultivars, owing to the higher harvest indexes of modern wheat cultivars. Regarding the comparison between cereals and legumes, Sadras (2006), reviewed different studies and compiled a database including different species groups (cereals, legumes and oilseed species). Sadras found that PUTE of cereals was higher than legumes (on average 116 vs. $78 \mathrm{~kg}$ yield kg P uptake ${ }^{-1}$, respectively). In addition to the importance PUTE differences among crops, the quantification of the potential PUTE of these crops (particularly in wheat and pea) is also important as a reference measure for the sustainability of these crops. It could be expected that PUTE values under high yielding environments are much higher than those previously reported. Therefore, it is necessary to compare this variable in a high yielding 
environment which allows the potential PUTE of these crops to be expressed. In addition, studies about these crops in volcanic soils (Andisols) will increase our understanding about crop differences in response to soils with high $\mathrm{P}$ fixation capacities.

Regarding PUPE, a variety of root traits, such as root biomass, root length density $\left(\mathrm{cm} \mathrm{cm}^{-3}\right)$ and specific root length $\left(\mathrm{m} \mathrm{g}^{-1}\right)$ are involved in the variation of PUPE among crops species and their genotypes (Gahoonia et al., 1999; Lynch, 2007). Larger roots provide greater root-soil contact which is particularly important for nutrients with lower mobility, such as P. On the other hand, the variation in specific root length, an indicator of root diameter, between crop species and genotypes is well documented (Gahoonia et al., 1999). Crops with higher specific root length may be more effective in absorbing $\mathrm{P}$ due to the larger soil volume per unit of root surface area and the lower maintenance carbon cost of thinner roots. However, the link between root diameter and $\mathrm{P}$ uptake is still unclear. In general, temperate cereals, such as wheat and barley have higher root length and specific root length than legumes under different water regimens (Gregory and Eastham 1996). However, legumes could compensate for their lower root length through a higher $\mathrm{P}$ uptake per unit of root length, since legumes have shown higher organic exudation than wheat (Nuruzzaman et al., 2006; Pearse et al., 2006); this increases $\mathrm{P}$ mobility and uptake (Hinsinger, 2001; Yang et al., 2013). Nevertheless, to the best of our knowledge, there are no studies comparing wheat and pea's $\mathrm{P}$ uptake and root traits under the same field experiments, which would allow us to elucidate possible differences between these crops in relation to this subject.

The aim of the present study was to comparatively evaluate the grain yield responses, phosphorus use efficiency, their components and related root traits of wheat and pea under field conditions in a high yielding environment with different $\mathrm{P}$ availabilities.

\section{Material and Methods}

\subsection{Site and experimental design}

Two field experiments were conducted in a Typic Hapludand soil (CIREN, 2003), located at the experimental station $\left(39^{\circ} 47^{\prime} \mathrm{S}, 73^{\circ} 14^{\prime}\right.$ W, 19 m a.s.1.) of Universidad Austral de Chile, Valdivia, Chile. The soils of both experiments belonged to the same soil series (Valdivia). Experiments were set up $300 \mathrm{~m}$ from one another in the same field. The soil in experiment 1 was higher in $\mathrm{pH}, \mathrm{Ca}$ and $\mathrm{Mg}$ than in experiment 2. However, in experiment 2, the $\mathrm{P}$ availability was higher $(35 \%)$ than in experiment 1 . Variations on other parameter as clay content, soil reactivity, physical properties and other chemicals characteristics has been previously measured in this soil series and it was fairly homogeneous in these characteristics (Huygens et al., 2011). In both experiments Al saturation was negligible (Table 1). Sowing dates were August 20th and September 12th for experiments 1 and 2, respectively. These sowing dates are within the optimal range for spring wheat and grain legumes. The objective of two experiments was to expose the crops to different environments and generate variability in biomass, yield and 
in biomass, yield and P uptake. Differences between experiments (different initial soil fertility and different sowing date) contributed to this aim. In both experiments, treatments consisted of a combination of (i) two crops and (ii) three $\mathrm{P}$ fertilization rates. The two crops were a springbred wheat (cv. Pandora-INIA) and pea (semileaflesscv cv. Nitouche). The $\mathrm{P}$ fertilization rates were 0 (PO), 100 (P1) and $250(\mathrm{P} 2) \mathrm{kg} \mathrm{P} \mathrm{ha}^{-1}$ as triple superphosphate $\left(46 \% \mathrm{P}_{2} \mathrm{O}_{5}\right)$. In both experiments factors were arranged in a split-plot design, where $\mathrm{P}$ rates were assigned to main plots and crops to sub-plots randomized into three blocks. At sowing, the $\mathrm{P}$ rates were incorporated into the soil up to a depth of $20 \mathrm{~cm}$ using a cultivator.

Table 1. Initial soil chemical properties in experiments 1 and 2.

\begin{tabular}{|c|c|c|c|c|c|c|c|c|c|}
\hline \multirow{2}{*}{ Experiment } & \multicolumn{2}{|c|}{$\mathrm{pH}(1: 2.5)$} & \multirow{2}{*}{$\begin{array}{l}\text { P-Olsen } \\
\mathrm{mg} \mathrm{kg}^{-1}\end{array}$} & $\mathrm{Ca}$ & $\mathrm{Mg}$ & $\mathrm{K}$ & $\mathrm{Na}$ & $\mathrm{Al}$ & Al satura \\
\hline & $\mathrm{H}_{2} \mathrm{O}$ & $\mathrm{CaCl}_{2}$ & & \multicolumn{5}{|c|}{$\mathrm{cmol}_{(+)} \mathrm{kg}^{-1}$} & $\%$ \\
\hline 1 & 6.50 & 6.00 & 9.7 & 9.30 & 1.57 & 0.61 & 0.11 & 0.04 & 0.32 \\
\hline 2 & 5.52 & 5.10 & 13.1 & 4.39 & 0.47 & 0.60 & 0.09 & 0.15 & 2.66 \\
\hline
\end{tabular}

$\mathrm{Al}$ saturation $\%=(\mathrm{Al} /(\mathrm{Ca}+\mathrm{Mg}+\mathrm{K}+\mathrm{Na}+\mathrm{Al})) \times 100$.

\subsection{Crop culture}

In both experiments seed rates of wheat and pea were 350 and 70 seed $\mathrm{m}^{-2}$, respectively. Each plot consisted of 9 three meter long rows. Row widths were 0.15 and $0.20 \mathrm{~m}$ for wheat (4.1 $\mathrm{m}^{2}$ ) and pea $\left(5.4 \mathrm{~m}^{2}\right)$, respectively. In order to achieve proper seed distribution along rows, strip paper containing seeds were used for wheat, while pea was hand-sown. Crops were fertilized with $100 \mathrm{~kg} \mathrm{~N}^{-1}$ (urea $46 \% \mathrm{~N}$ ) and $150 \mathrm{~kg} \mathrm{~K} \mathrm{ha}{ }^{-1}$ (muriate of potash $60 \% \mathrm{KCl}$ ) at sowing and complemented with $150 \mathrm{~kg} \mathrm{~N} \mathrm{ha}^{-1}$ at the beginning of tillering in wheat and at vegetative node number 8 in pea. At sowing all fertilizers were incorporated into the soil with a cultivator up to a soil depth of $20 \mathrm{~cm}$. To avoid water shortages all plots were surface-irrigated weekly from flowering to harvest (Exp. 1: 200 mm; Exp. 2: $244 \mathrm{~mm}$ ). The experiments were maintained free of biotic stresses. Thus, weeds were periodically removed by hand, while diseases and insects were prevented with the use of fungicides and insecticides at the rates recommended by their manufacturers.

\subsection{Above-ground measurements}

In each plot nine samples of above-ground biomass were taken during the crop cycle, including the last measurement at physiological maturity. Before physiological maturity, $0.5 \mathrm{~m}$ long samples were taken from inner rows without edge effects, while at harvest (physiological maturity) yield was determined using $1 \mathrm{~m}$ long samples taken from the central row. Wheat 
samples were separated into green and senescent leaves and stems plus leaf sheaths in addition to spikes when they were present. Pea samples were separated into stems plus tendrils, green and senescent stipules, and pods and grains when they were present. All samples were weighed with an electronic balance (Mettler Toledo XP205DR, Greifensee, Switzerland) after oven drying for $48 \mathrm{~h}$ at $65^{\circ} \mathrm{C}$. Pods and spikes were counted and threshed by hand to record the grain yield. Grain weight was determined as the average weight of three sub-samples containing 100 grains. The seasonal radiation use efficiency (RUE, $g$ of biomass $\mathrm{MJ}^{-1}$ ) was calculated as the ratio between the total above-ground biomass and the total intercepted solar radiation during the crop cycle. The methodology of radiation measurements and climatic conditions were previously described by Sandaña et al. (2012). P concentration was measured in above-ground biomass samples using the phospho-vanademolybdate yellow method.

According to Moll et al. (1982), PUTE was calculated as the ratio between grain yield and the $\mathrm{P}$ uptake in above-ground biomass at harvest. While the PUPE was calculated as the ratio between the $\mathrm{P}$ uptake in above-ground biomass and soil $\mathrm{P}$ availability. $\mathrm{P}$ available was estimated as the sum of $\mathrm{P}$ availability at sowing (P-Olsen at the top $20 \mathrm{~cm}$ of soil) plus $\mathrm{P}$ fertilization rates. Finally, PUE was calculated as the product of PUTE (Grain yield $\left(\mathrm{g} \mathrm{m}^{-2}\right) / P$ uptake $\left.\left(\mathrm{g} \mathrm{m}^{-2}\right)\right)$ and PUPE (P uptake $\left(\mathrm{g} \mathrm{m}^{-2}\right) / P$ available $\left.\left(\mathrm{g} \mathrm{m}^{-2}\right)\right)$.

\subsection{Root measurements}

Both crops' roots were sampled at flowering, considering that at this stage maximum root biomass is reached in field crops. Soil samples were taken in each plot up to a soil depth of 50 $\mathrm{cm}$ using a soil core sampler ( $5 \mathrm{~cm}$ of diameter). In each plot 3 samples were taken between rows and 3 samples on rows. Each soil sample was separated into sections of 0-10, 10-20, 20-30 and 30-50 cm. Samples of each layer were grouped. Roots at different soil depths were carefully separated by hand using a $2 \mathrm{~mm}$ diameter sieve. Roots were gently washed with water to remove soil and free them of impurities. Then, the excess water was removed with paper towels. The root length from each soil layer was measured using WinRhizo software. Previously, WinRhizo software was calibrated using the Tennant's intersection method (Tennant, 1975) and a scanner image. Then, root biomass was measured with an electronic balance after root samples were oven dried at $60^{\circ} \mathrm{C}$ for $72 \mathrm{~h}$. Total root length was calculated as the sum of each root length from the four soil layers. Specific root length was calculated as the ratio between the total root length and the total root biomass.

\subsection{Statistical analysis}

The effects of treatments on crop variables were assessed by two-way analysis of variance for split-plot design. Regression analyses were used to assess the associations between variables. Regression coefficients were compared with the Student's t test.

\section{Results}

\subsection{Phenology and climatic conditions}

Phenology and climatic conditions were previously described by Sandaña et al. (2012). 
Briefly, wheat showed a longer crop cycle than pea. The duration of wheat's emergencephysiological maturity period under P2 was 150 and 142 days in experiment 1 and 2, respectively, while in pea this phase lasted 142 and 128 days, respectively. $P$ fertilizations had little effect on the length of the crop cycle since (i) in P0 treatment the crop cycle was delayed, on average, by 6 and 5 days for wheat and pea, respectively and (ii) in both crops no differences were found between treatments $\mathrm{P} 1$ and $\mathrm{P} 2$. Across experiments, average air temperatures before and after flowering were 10 and $14{ }^{\circ} \mathrm{C}$, respectively. Incident solar radiations before and after flowering were 17.6 and $23.0 \mathrm{MJ} \mathrm{m}^{-2}$, respectively.

\subsection{Above-ground biomass, grain yield and main components}

According to climatic conditions and crop management, in both experiments crops reached high above-ground biomass and grain yield when were exposed to the highest $\mathrm{P}$ rate (on average, wheat pea reached grain yields 11 and 6 tones/ha, respectively) (Table 2).AGB and GY were affected by the $\mathrm{P}$ rate, crop and $\mathrm{P}$ rate $\mathrm{x}$ crop interaction (Table 2). Wheat was more sensitive to $\mathrm{P}$ deficiency than pea. On average, relative to the highest $\mathrm{P}$ rate wheat's AGB was reduced by 42 and $16 \%$ under $\mathrm{P} 0$ and $\mathrm{P} 1$ treatments, while in pea these reductions were 30 and $9 \%$, respectively (Table 2). Similarly, wheat's grain yield was reduced, on average, by 41 and $18 \%$ in P0 and P1 treatments, respectively; whereas in pea these reductions were 31 and $8 \%$, respectively. Both crops' GY variations were highly related $\left(R^{2}=0.99, P<0.01\right)$ to $\mathrm{AGB}$ and not to HI (Figure 1 $a, b$ ). Across experiments, the total above-ground biomass was highly related to the total intercepted solar radiation during the crop cycle (Figure 1c). Wheat also showed higher $(78 \%)$ radiation use efficiency than pea. In both crops, grain yield responses were related $(P<0.01)$ principally to changes in grain number (Table 2).
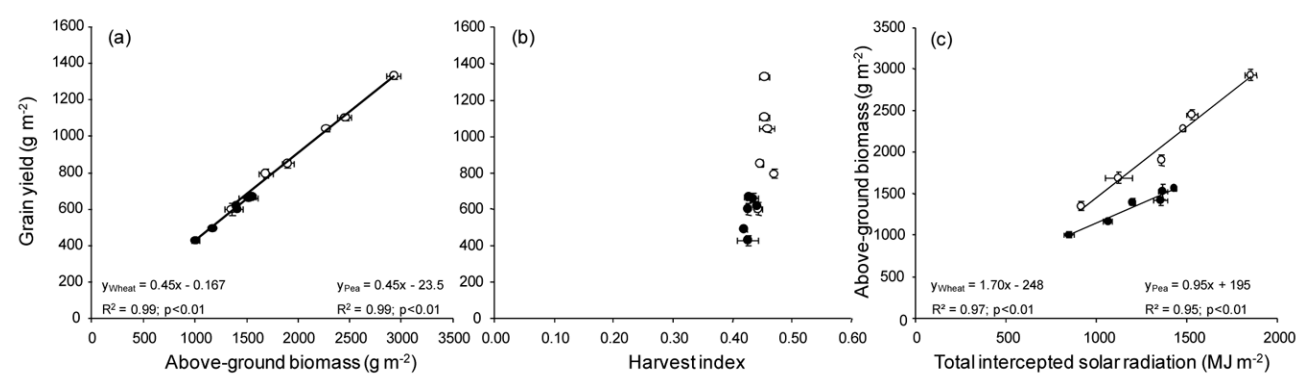

Figure 1. Relationship between grain yield and above-ground biomass (a); between grain yield and harvest index (b) and between above-ground biomass and total intercepted radiation during the crop cycle (c) of wheat (open circles) and pea (closed circles) in experiments 1 and 2. Vertical and horizontal bars show the standard error of the mean when they are larger than the size of the symbols. 
Table 2. Above-ground biomass (AGB), grain yield (GY), harvest index (HI), grain number (GN) and average grain weight $(\mathrm{GW})$ of wheat and pea under different $\mathrm{P}$ rate in experiments 1 and 2 .

\begin{tabular}{|c|c|c|c|c|c|c|c|}
\hline Experiments & Crops & $P$ rate & $\begin{array}{c}\text { AGB } \\
\left(\mathrm{g} \mathrm{m}^{-2}\right)\end{array}$ & $\begin{array}{c}\mathrm{GY} \\
\left(\mathrm{g} \mathrm{m}^{-2}\right)\end{array}$ & $\mathrm{HI}$ & $\begin{array}{c}\mathrm{GN} \\
\left(\mathrm{m}^{-2}\right)\end{array}$ & $\begin{array}{c}\text { GW } \\
\left(\mathrm{mg} \mathrm{grain}^{-1}\right)\end{array}$ \\
\hline \multirow[t]{10}{*}{1} & \multirow[t]{3}{*}{ Wheat } & P0 & 1690 & 793 & 0.47 & 16369 & 48.7 \\
\hline & & $\mathrm{P} 1$ & 2453 & 1104 & 0.45 & 22173 & 49.8 \\
\hline & & $\mathrm{P} 2$ & 2930 & 1329 & 0.45 & 25370 & 52.5 \\
\hline & \multirow[t]{6}{*}{ Pea } & $\mathrm{P} 0$ & 1169 & 493 & 0.42 & 1923 & 257 \\
\hline & & $\mathrm{P} 1$ & 1412 & 600 & 0.43 & 2295 & 261 \\
\hline & & $\mathrm{P} 2$ & 1562 & 668 & 0.43 & 2594 & 258 \\
\hline & & $\mathrm{P}$ level (P) & $* *$ & $* *$ & n.s. ${ }^{b}$ & $* *$ & n.s. \\
\hline & & Crop (C) & $* *$ & $* *$ & $* *$ & $* *$ & $* *$ \\
\hline & & $\mathrm{P} \times \mathrm{C}$ & $* *$ & $* *$ & n.s. & $* *$ & n.s. \\
\hline & \multicolumn{2}{|c|}{ S.E.M. $^{a}($ d.f. $=6)$} & 49.1 & 18.4 & 0.008 & 542 & 3.20 \\
\hline \multirow[t]{10}{*}{2} & \multirow[t]{3}{*}{ Wheat } & P0 & 1353 & 600 & 0.44 & 11696 & 51.3 \\
\hline & & $\mathrm{P} 1$ & 1901 & 849 & 0.45 & 17358 & 49.3 \\
\hline & & $\mathrm{P} 2$ & 2274 & 1042 & 0.46 & 19811 & 52.7 \\
\hline & \multirow[t]{6}{*}{ Pea } & $\mathrm{P} 0$ & 1005 & 428 & 0.43 & 1634 & 262 \\
\hline & & $\mathrm{P} 1$ & 1399 & 617 & 0.44 & 2387 & 258 \\
\hline & & $\mathrm{P} 2$ & 1522 & 661 & 0.43 & 2550 & 259 \\
\hline & & $\mathrm{P}$ & $* *$ & $* *$ & n.s. & $* *$ & n.s. \\
\hline & & $\mathrm{C}$ & $* *$ & $* *$ & n.s. & $* *$ & $* *$ \\
\hline & & $\mathrm{P} \times \mathrm{C}$ & $*$ & $* *$ & n.s. & $* *$ & n.s. \\
\hline & \multicolumn{2}{|c|}{ S.E.M. $($ d.f. $=6)$} & 61.4 & 17.7 & 0.012 & 640 & 3.10 \\
\hline
\end{tabular}

n.s.: not significant; $* P<0.05$; $* *<0.01$; S.E.M.: Standard error of the means.

\subsection{P concentration and $P$ uptake}

At harvest, the $\mathrm{P}$ concentration in aboveground biomass was affected $(P<0.01)$ by the crop and $P$ rates. Averaged across experiments and treatments, the $\mathrm{P}$ concentrations of wheat and pea at harvest were 0.11 and $0.17 \%$, respectively (Table 3 ). When $\mathrm{P}$ concentrations were related to the above-ground biomass of all of the samples, the effects of both P supply and the crops were evident (Figure 2). In both crops, the $\mathrm{P}$ concentration decreased with the increment of above-ground biomass. P uptake at harvest was affected $(P<0.01)$ by the $\mathrm{P}$ rates and not by the crop. Averaged across experiments, the $\mathrm{P}$ uptakes of wheat and pea were 2.25 and $2.35 \mathrm{~g} \mathrm{P} \mathrm{m}^{-2}$, respectively. Relative to $\mathrm{P} 0$, the $\mathrm{P}$ uptakes of wheat and pea increased, on average, by 88 and $57 \%$ in response to the $\mathrm{P} 2$ rate, respectively (Table 3 ).

\subsection{Phosphorus use efficiency}

Across experiments, both above-ground biomass and grain yield of wheat and pea were positively and highly related $\left(\mathrm{R}^{2}>0.88\right.$, $P<0.01$ ) to $\mathrm{P}$ uptake (Fig. $3 a, b$ ). However, the regression coefficients of wheat and pea 
were different $(P<0.01)$. These slopes show the high PUTE reached by wheat and pea for both above-ground biomass and grain yield production, respectively. In both experiments, wheat showed a consistently higher $(P<$ 0.01) PUTE than pea, averaging 430 and 249 $\mathrm{g}$ of yield $\mathrm{g}^{-1} \mathrm{P}$ uptake, respectively (Table 3 ).

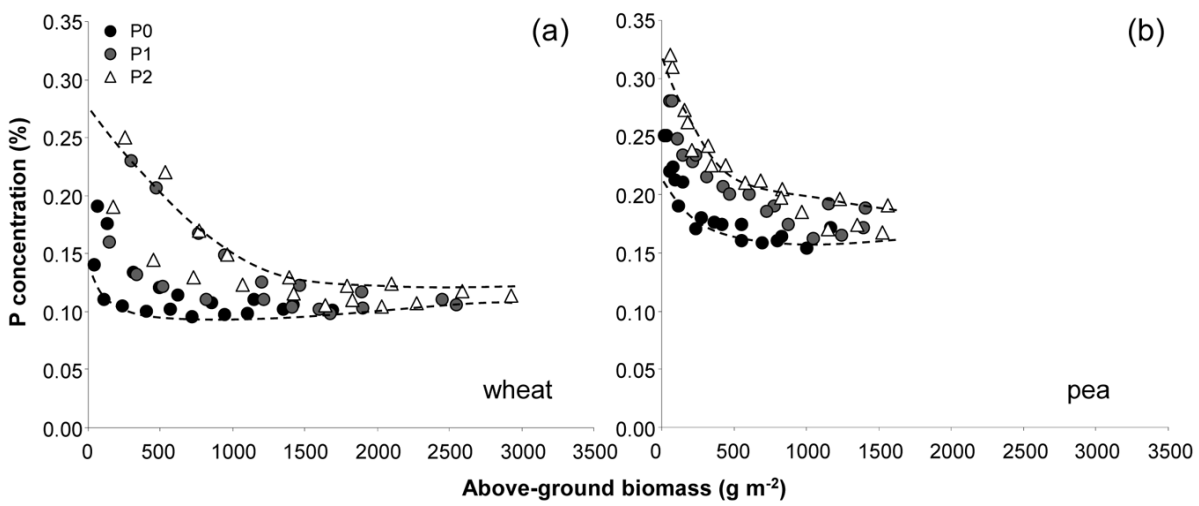

Figure 2. Relationship between P concentration and above-ground biomass of wheat (a) and pea (b) under three P rates. All samples from experiments land 2 are included. Dashed lines were visually fitted to indicate the upper and lower limit of $\mathrm{P}$ concentration.

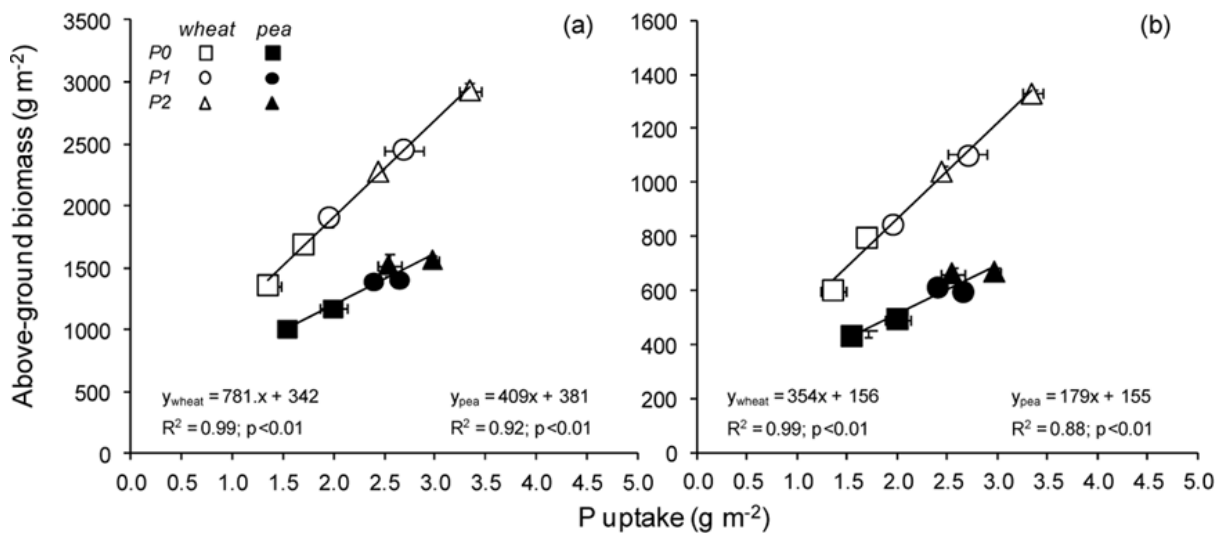

Figure 3. Relationship of above-ground biomass (a) and grain yield (b) with P uptake of wheat (white symbols) and pea (black symbols) in experiments 1 and 2. Vertical and horizontal bars represent 2 standard errors of the means when they are larger than symbols. 

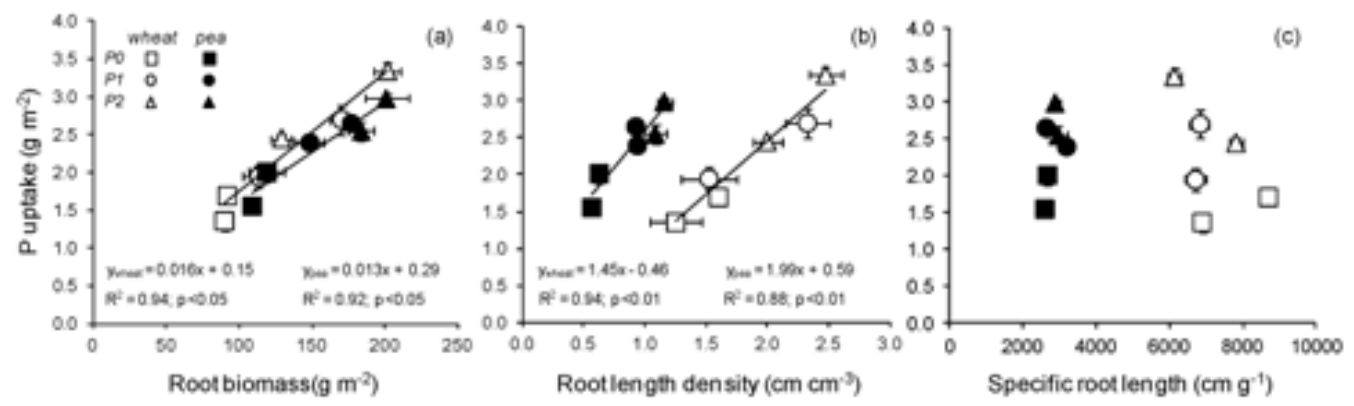

Figure 4. Relationship between $P$ uptake at harvest with root biomass (a), root length density (b) and specific root length (c) in wheat (white symbols) and pea (black symbols) in experiments 1 and 2. Vertical and horizontal bars represent 2 standard errors of the means when they are larger than symbols.

In contrast to PUTE, wheat and pea showed similar PUPE values. Wheat and pea's PUPE, averaged across experiments, was 0.44 and $0.49 \mathrm{~g} \mathrm{P} \mathrm{g}^{-1} \mathrm{P}$ available, respectively (Table $3)$. Only in experiment 2 did wheat have lower $(11 \%)(P<0.05)$ PUPE than pea. Despite the similar ranges of PUPE displayed by these crops, wheat and pea showed different strategies in order to meet the P demand. In both crops, $\mathrm{P}$ uptake was positively related $(P<0.05)$ to both root biomass per square meter and root length density (Figure 4 $a, b)$. However, pea had similar $\mathrm{P}$ uptake to wheat, but with a lower root length density than wheat (Figure $4 b$ ). On the other hand, in both crops $\mathrm{P}$ uptake was not related to the specific root length and wheat showed higher specific root length than pea (Figure $4 c$ ). In consequence, pea showed consistently higher (2.3 fold) $(P<0.01)$ P uptake per unit of root length than wheat (Figure 5).

In both experiments, PUE (PUTE $x$ PUPE) was affected $(P<0.01)$ by $\mathrm{P}$ rate, crop and $\mathrm{P} x$ crop interaction (Table 3). Wheat showed higher PUE than pea. On average, wheat and pea's PUE was

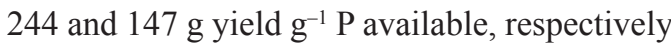
in experiment 1, while in experiment 2 these

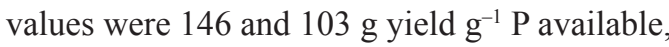
respectively. Across experiments, $\mathrm{P} 1$ and $\mathrm{P} 2$ decreased the PUE of both crops by between 77 and $93 \%$, when compared to P0; these declines were mainly ascribed to reductions in PUPE (Table 3). 
Table 3. Total $\mathrm{P}$ concentration, total $\mathrm{P}$ uptake, $\mathrm{P}$ utilization efficiency (PUTE), $\mathrm{P}$ uptake efficiency (PUPE) and P use efficiency (PUE) of wheat and pea under different P rates in experiments 1 and 2.

\begin{tabular}{|c|c|c|c|c|c|c|c|}
\hline Experiments & Crops & $P$ rates & $\begin{array}{l}\mathrm{P} \\
(\%)\end{array}$ & $\begin{array}{l}\text { P uptake } \\
\left(\mathrm{g} \mathrm{m}^{-2}\right)\end{array}$ & $\begin{array}{c}\text { PUTE } \\
\text { (g yield / } \mathrm{g} \text { P uptake) }\end{array}$ & $\begin{array}{c}\text { PUPE } \\
\text { (g P uptake / g P available) }\end{array}$ & $\begin{array}{c}\text { PUE } \\
\text { ( } \mathrm{g} \text { yield } / \mathrm{g} \text { P available) }\end{array}$ \\
\hline \multirow[t]{10}{*}{1} & \multirow[t]{3}{*}{ Wheat } & P0 & 0.10 & 1.70 & 470 & 1.25 & 584 \\
\hline & & P1 & 0.11 & 2.70 & 413 & 0.24 & 97 \\
\hline & & P2 & 0.11 & 3.34 & 399 & 0.13 & 50 \\
\hline & \multirow[t]{6}{*}{ Pea } & P0 & 0.17 & 2.00 & 248 & 1.47 & 363 \\
\hline & & P1 & 0.19 & 2.65 & 227 & 0.23 & 53 \\
\hline & & P2 & 0.19 & 2.98 & 225 & 0.11 & 25 \\
\hline & & P level (P) & $*$ & $* *$ & * & $* *$ & $* *$ \\
\hline & & Crop (C) & $* *$ & n.s. & $* *$ & n.s. & $* *$ \\
\hline & & $\mathrm{P} \times \mathrm{C}$ & n.s. & n.s. & n.s. & n.s. & $* *$ \\
\hline & \multicolumn{2}{|c|}{ S.E.M. (D.F. $=6$ ) } & 0.008 & 0.145 & 21.1 & 0.061 & 10.91 \\
\hline \multirow[t]{10}{*}{2} & \multirow[t]{3}{*}{ Wheat } & $\mathrm{P} 0$ & 0.10 & 1.36 & 436 & 0.76 & 327 \\
\hline & & P1 & 0.10 & 1.95 & 437 & 0.16 & 72 \\
\hline & & P2 & 0.11 & 2.44 & 426 & 0.09 & 39 \\
\hline & \multirow[t]{6}{*}{ Pea } & P0 & 0.15 & 1.55 & 277 & 0.84 & 233 \\
\hline & & P1 & 0.17 & 2.39 & 258 & 0.20 & 52 \\
\hline & & P2 & 0.17 & 2.55 & 260 & 0.09 & 25 \\
\hline & & $\mathrm{P}$ & * & $* *$ & n.s. & $* *$ & $* *$ \\
\hline & & $\mathrm{C}$ & $* *$ & n.s. & $* *$ & $* *$ & $* *$ \\
\hline & & $\mathrm{P} \times \mathrm{C}$ & n.s. & n.s. & n.s. & $* *$ & $* *$ \\
\hline & S.E & $(\mathrm{D} . \mathrm{F} .=6)$ & 0.003 & 0.07 & 9.57 & 0.009 & 4.79 \\
\hline
\end{tabular}

n.s.: not significant; $* P<0.05 ; * * P<0.01$; S.E.M.: Standard error of the means.

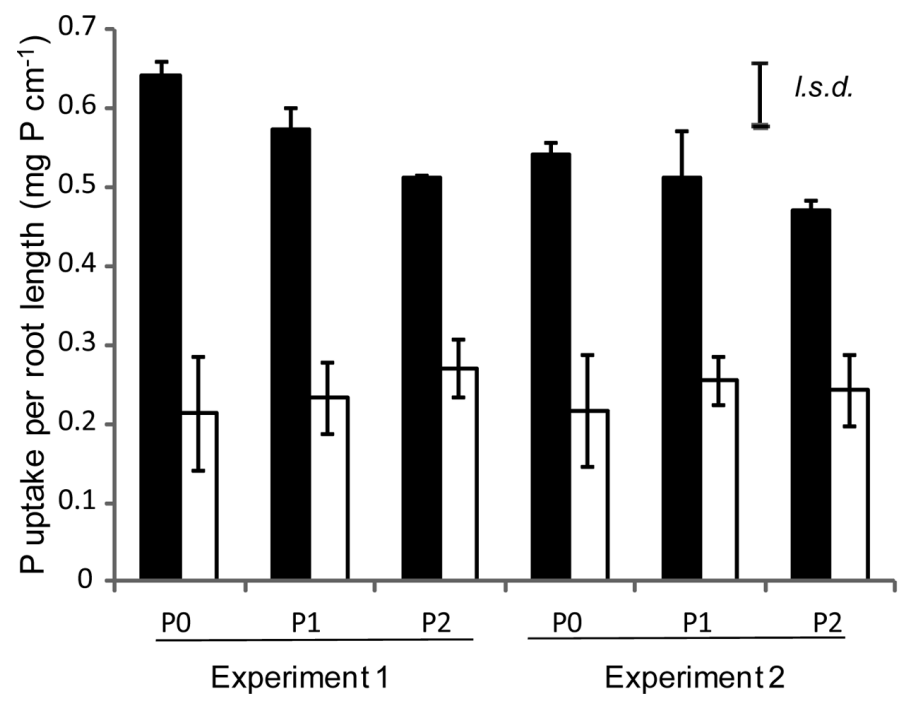

Figure 5. $\mathrm{P}$ uptake per unit of root length of wheat (white bars) and pea (black bars) in experiments 1 and 2. Verticals bars represent 2 standard errors of the means. L.s.d.: Least significant difference value $(P=0.05)$. 


\section{Discussion}

The two experiments of the present study, allowed the crops growth in different environments and generate important variability in biomass and yield. The climatic conditions and crop management practices allowed the genetic yield potential of both wheat and pea to be expressed in the highest $\mathrm{P}$ rate. This is in line with previous studies including these crops maintained free of biotic and abiotic stresses in the high yielding environment of southern Chile (wheat: Bustos et al., 2013; pea: Sandaña et al., 2009). For example, for the same cultivar Pandora-INIA, Bustos et al. (2013), reported grain yield, accumulated intercepted photosynthetically active radiation (IPAR) and radiation use efficiency (RUE) equivalent to 11 $\mathrm{Mg} \mathrm{ha}^{-1}, 878 \mathrm{MJ} \mathrm{m}^{-2}$ y $3.0 \mathrm{~g} \mathrm{MJ}^{-1}$, respectively. These values are similar to those reached in our study under the highest $\mathrm{P}$ rate (the IPAR and RUE were on averaged $833 \mathrm{MJ} \mathrm{m}^{-2}$ and $3.2 \mathrm{~g} \mathrm{MJ}^{\mathrm{J}}$ ${ }^{1}$, respectively). As in previous studies on wheat and other cereals, wheat's grain yield responses to P supply were related to the total AGB and not to HI (wheat: Manske et al., 2001; Aulakh et al., 2003; Sandaña and Pinochet, 2011). More interestingly, the present study showed that HI was also conservative in pea. There are no previous studies about this subject on pea, but similarly, in soybean the above-ground biomass was more variable than $\mathrm{HI}$ at field conditions under different $\mathrm{P}$ availabilities (Aulakh et al., 2003). These results suggest that the aboveground biomass production of wheat and pea under $\mathrm{P}$ deficiency is much less conservative than its partitioning to yield. This information could be useful for modelers interested in simulating grain yield responses through biomass accumulation and its partitioning to yield under P deficiency.

PUE differences between wheat and pea were principally related to the contrasting PUTE in these crops. The higher PUTE shown by wheat is in agreement with other studies comparing cereals and legumes (Sadras, 2006). Sadras (2006), found that cereals' PUTE was $49 \%$ higher than that of legumes. Pea's low PUTE could be ascribed to a higher biomass allocation to roots than wheat. However, in the present study wheat and pea showed similar ranges of root biomass per square meter under different $P$ rates. Therefore, the higher specific rates of respiration and high production value of grains may be the principal factors behind pea's low PUTE (Sadras, 2006). More interestingly, the present study showed higher PUTE values (on average $430 \mathrm{~kg}$ yield $\mathrm{kg}^{-1} \mathrm{P}$ uptake) for wheat than previous studies, averaging 356 and $223 \mathrm{~kg}$ yield $\mathrm{kg}^{-1} \mathrm{P}$ uptake (Manske et al., 2001) which represent an average gap of $32 \%$ in PUTE. On the other hand, pea's PUTE (on average 233 $\mathrm{kg}$ yield $\mathrm{kg}^{-1} \mathrm{P}$ uptake) seems to be very high compared to the average PUTE of others legumes (78 $\mathrm{kg}$ yield $\mathrm{kg}^{-1} \mathrm{P}$ uptake) analyzed by Sadras (2006). Wheat and pea's high PUTE could be ascribed to the higher harvest index, yield and lower $\mathrm{P}$ concentration found in our investigation compared to previous studies; these are desirable traits to improve crops' PUTE (Batten, 1992).

Due to the low mobility of $\mathrm{P}$ in soils, root growth is very important for $\mathrm{P}$ acquisition (Föhse et al., 1988; Watt and Evans, 2003; Lynch, 2007). The present study represents the first attempt to evaluate relationships between root traits and $\mathrm{P}$ uptake in wheat and pea under field conditions. Interestingly, for similar ranges in PUPE, the data presented 
here highlights two strategies for P acquisition. Wheat showed higher root length and, therefore, a higher capacity to explore the soil for $P$ acquisition than pea. However, on the other hand, pea had higher P uptake rate per root length than wheat, compensating for its smaller root systems. This agrees with Föhse et al. (1988) who showed, in a comparative study in pots, that some species produce large root systems, like wheat and ryegrass, while others have a higher uptake per unit of root length, like rape and spinach. Similarly, Watt and Evans (2003) showed that soybeans grown in pots had a greater soil volume colonized by roots than lupin, 26 vs. $8 \%$, respectively. However, lupin had, on average, 2.6 times more $\mathrm{P}$ uptake per root length than soybean. A compensatory mechanism between root growth and $\mathrm{P}$ uptake per surface root area was observed in different genotypes of common bean (Araújo et al., 1998). The high P uptake per unit root length shown by pea (2.3 fold) indicates that this crop acquires its $\mathrm{P}$ through a mechanism other than root extension. Other mechanisms of $\mathrm{P}$ acquisition include higher root exudation, longer root hairs and higher activity and quantity of $\mathrm{P}$ transporters (Watt and Evans, 2003; Nuruzzaman et al., 2006; Pearse et al., 2006). In addition, the fungal community in the rhizosphere of legumes and cereals has shown to be different with potential effect in arbuscular mycorrhizal (AM) colonization and P mobilization (Wang et al., 2012). We did not measure these mechanisms; however, in previous studies legumes have shown to have higher organic exudation than wheat (Nuruzzaman et al., 2006; Pearse et al., 2006). Nonetheless, studies comparing root hairs of these crops at field conditions are needed since this trait has been an important mechanism behind crop differences in $\mathrm{P}$ acquisition (Gahoonia et al., 1999).

\section{Conclusion}

In conclusion, the present study showed that wheat had higher phosphorus use efficiency than pea mainly due to wheat's higher phosphorus utilization efficiency. Wheat and pea absorbed similar amounts of $\mathrm{P}$; though, wheat achieved this through higher above-ground biomass and yield, but with a lower $\mathrm{P}$ concentration than pea. On the other hand, phosphorus uptake efficiency was slightly different in wheat and pea. Both crops' $\mathrm{P}$ uptake was related to root biomass and root length density, and not to the specific root length. Wheat and pea showed contrasting strategies to absorb $\mathrm{P}$ because with similar root biomasses wheat had a higher soil exploratory capacity than pea, but pea compensated for this trait with higher $\mathrm{P}$ uptake per root length than wheat. The present study shows the superiority of wheat in terms of phosphorus use efficiency compared to pea; however, crop differences are ascribed to differences in phosphorus utilization rather than to phosphorus uptake efficiency.

\section{Acknowledgments}

The revision of English usage by Christine Harrower (Universidad Austral de Chile) is highly appreciated. This study was financed by the RHIBAC Project of European Community (RUE32) and the Scientific and Technical Research Council of Chile (CONICYT), project FONDECYT 1010163. Patricio Sandaña held a postgraduate scholarship from CONICYT-2010. 


\section{References}

Araújo, A.P., Teixeira, M.G., De Almeida, D.I. 1998. Variability of traits associated with phosphorus efficiency in wild and cultivated genotypes of common bean. Plant Soil. 203, 173-182.

Aulakh. M., Pasricha, N., Bahl, G. 2003. Phosphorus fertilizer response in an irrigated soybean-wheat production system on a subtropical, semiarid soil. Field Crops Res. 80, 99-109.

Balemi, T., Negisho, K. 2012. Management of soil phosphorus and plant adaptation mechanisms to phosphorus stress for sustainable crop production: a review. J. Soil Sci. Plant Nutr. 12, 547-561.

Batten, G.D. 1992. A review of phosphorus efficiency in wheat. Plant Soil. 146, 163-168.

Bolland, M., Siddique, K., Loss, S., Baker, M. 1999. Comparing responses of grain legumes, wheat and canola to applications of superphosphate. Nutr. Cycl. Agroecosys. 53, 157-175.

Bustos, D.V., Hasan, A.K., Reynolds, M.P., Calderini, D.F. 2013. Combining high grain number and weight through a DH-population to improve grain yield potential of wheat in high-yielding environments. Field Crops Res. 145, 106-115.

Calderini, D.F., Torres-León, S., Slafer, G.A. 1995. Consequences of wheat breeding on nitrogen and phosphorus yield, grain nitrogen and phosphorus concentration and associated traits. Ann. Bot. 76, 315-322.

CIREN, 2003. In: Centro de Recursos Naturales. Estudio agrológico X Reg. Tomo 2, Santiago Chile, 956-7153-49-3p. 412.
Cordell, D., Drangert, J., White, S. 2009.The story of phosphorus: Global food security and food for thought. Glob. Environ. Change. 19, 292-305.

Elser, J., Bennett, D. 2011. Phosphorus Cycle: A broken biogeochemical cycle. Nature. 478, 29-31.

Föhse, D., Classen, N., Junk, A. 1988. Phosphorus efficiency of plants. I. External and internal $\mathrm{P}$ requirement and $\mathrm{P}$ uptake efficiency of different plant species. Plant Soil. 110, 101-109.

Gahoonia, T., Nielsen, N., Lyshede, O. 1999. Phosphorus (P) acquisition of cereal cultivars in the field at three levels of P fertilization. Plant Soil. 211, 269-281.

Gregory, P., Eastham, J. 1996. Growth of shoots and roots, and interception of radiation by wheat and lupin crops on a shallow, duplex soil in response to time of sowing. Aust. J. Agric. Res. 47, 427-447.

Hinsinger, P. 2001. Bioavailability of soil inorganic $\mathrm{P}$ in the rhizosphere as affected by root-imduced chemical changues: a review. Plant Soil. 237, 173-195.

Huygens, D., Schouppe, J., Roobroeck, D., Alvarez, M, Balocchi, O., Valenzuela, E., Pinochet, D., Boeckx, P. 2011. Drying-rewetting effects on N cycling in grassland soils of varying microbial community composition and management intensity in south central Chile. Appl. Soil Ecol. 48, 270-279.

Lynch, J. 2007. Roots of the second green revolution. Aust. J. Bot. 55, 493-512.

Manske, G., Ortiz-Monasterio, J., Van Ginkel, M., González, R., Fischer, R., Rajaram, S., Vlek, P. 2001. Importance of uptake efficiency versus $\mathrm{P}$ utilization for wheat yield 
in acid and calcareous soils in Mexico. Eur. J. Agron. 14, 261-274.

Moll, R.H., Kamprath, E.J., Jackson, W.A. 1982. Analysis and interpretation of factors which contribute to efficiency to nitrogen utilization. Agron. J. 74, 562-564.

Nuruzzaman, M., Lambers, H., Bolland, M., Veneklaas, E. 2006. Distribution of carboxylates and acid phosphatase and depletion of different phosphorus fractions in the rhizosphere of a cereal and three grain legumes. Plant Soil. 281, 109-120.

Pearse, S., Veneklaas, E., Cawthray, G., Bolland, M., Lambers, H. 2006. Carboxylate release of wheat, canola and 11 grain legume species as affected by phosphorus status. Plant Soil. 288, 127-139.

Sadras, V.O. 2006. The N:P stoichiometry of cereal, grain legume and oilseed crops. Field Crops Res. 95, 13-29.

Sandaña, P., Harcha, C.I., Calderini, D.F. 2009. Sensitivity of yield and grain nitrogen concentration of wheat, lupin and pea to source reduction during grain filling. A comparative survey under high yielding conditions. Field Crops Res. 114, 233-243.

Sandaña, P., Pinochet, D. 2011. Ecophysiological determinants of biomass and grain yield of wheat under P deficiency. Field Crops Res. 120, 311-319.

Sandaña, P., Ramírez, M., Pinochet, D. 2012. Radiation interception and radiation use efficiency of wheat and pea under different P availabilities. Field Crops Res. 127, 44-50.
Tennant, D. 1975. A test of a modified line intersect method of estimating root length. J. Ecol. 63, 995-1001.

Tilman, D., Fargione, J., Wolff, B., D'Antonio, C., Dobson, A., Howarth, R., Schindler, D., Schlesinger, W., Simberloff, D., Swackhamer, D. 2001. Forecasting Agriculturally Driven Global Environmental Change. Science. 292, 281-284.

Vance, C., Ehde-Stone, C., Allan, D. 2003. Phosphorus acquisition and use: critical adaptations by plants for securing a nonrenewable resource. New Phytol. 157, 423-447.

Watt, M., Evans, J. 2003. Phosphorus acquisition from soil by white lupin (Lupinus albus L.) and soybean (Glycine max L.), species with contrasting root development. Plant Soil. 248, 271-283.

Wang, Y., Marschner, P., Zhang, F. 2012 Phosphorus pools and other soil properties in the rhizosphere of wheat and legumes growing in three soils in monoculture or as a mixture of wheat and legume. Plant Soil. 354, 283-298.

Yang, S., Zhang, Z., Cong, J., Wang, X., Shi, S. 2013. Effect of fulvic acid on the phosphorus availability in acid soil. J. Soil Sci. Plant Nutr. 13, 526-533. 